\title{
Analytical Hydration Model for Filler Rich Binders in Self-compacting Concrete
}

\author{
Anne-Mieke Poppe ${ }^{1}$ and Geert De Schutter ${ }^{2}$
}

Received 7 December 2005, accepted 18 May 2006

\begin{abstract}
High filler contents are generally added to the cementitious system for the realisation of self-compacting concrete. Inert filler materials can be used to avoid problems caused by excessive hydration generated heat during hardening. Two different filler types were considered in this research: limestone and quartzite filler, combined with different types of Portland cement.

Although the above-mentioned filler materials are considered to be inert with respect to cement hydration, experimental research shows that they interfere with the hydration processes. On the one hand, the reaction speed may be influenced due to the possibility of modified nucleation. On the other hand, the reaction mechanism is also altered due to the presence of the large filler content, with the occurrence of a new hydration peak, especially in the case of limestone filler.

Based on isothermal conduction calorimetry on different cement filler systems, an existing hydration model for blended cement was modified for cement filler systems. Within the hydration-based hydration model for filler rich cementitious systems, the cement powder ratio is an important parameter. The analytical model was found to allow accurate prediction of the heat of hydration during the hardening process. This was also verified by means of adiabatic hydration tests on concrete.
\end{abstract}

\section{Introduction}

The realization of self-compacting concrete requires the combination of high flowability and high segregation resistance. This is made possible by the use of superplasticizers and viscosity enhancing agents combined with high concentrations of fine particles (Noguchi and Mori 1998, Okamura and Ouchi 1999). However, these high concentrations of powder materials (cement and fillers) can lead to the generation of high heat from hydration, which may in turn cause problems during hardening.

The existing literature contains very little information on the development of hydration heat in selfcompacting concrete (SCC).

An extended research program on SCC is currently being implemented at the Magnel Laboratory for Concrete Research, Ghent University. One of the research topics within this project deals with heat generation in SCC during hardening. As part of this research, isothermal hydration tests were carried out to evaluate heat generation in SCC. The results of these tests were compared with the results obtained for traditional concrete, and the applicability to SCC of an existing degree of hydration based hydration model was investigated.

\footnotetext{
${ }^{1}$ Magnel Laboratory for Concrete Research, Ghent University, Belgium.

E-mail: AnneMieke.Poppe@UGent.be

${ }^{2}$ Professor, Magnel Laboratory for Concrete Research, Ghent University, Belgium.
}

\section{Experimental determination of hydration heat: isothermal hydration tests}

To evaluate heat generation in isothermal conditions, conduction calorimetry was used. This test was carried out on small samples of cement paste, thus excluding any influences of aggregate particles. An extensive description of the conduction method can be found in several national codes, e.g. the Belgian Standard NBN B12213.

To allow a thorough study of heat generation, isothermal hydration tests were carried out on pure cement as well as on mixtures of cement and filler. Two different fillers (a limestone filler originating from Marquise, France, and a quartzite filler originating from Mol, Belgium) were combined with different portland cements (CEM I 42.5 R, CEM I 52.5 and CEM I 52.5 HSR LA). In this first stage of the research, these tests were carried out using no chemical admixtures such as superplasticizers and viscosity enhancing agents.

Table 1 gives the composition of the powder mixes used in the tests. Four different compositions were considered, each of which was repeated for the different cement-filler combinations, at three different temperature levels $\left(10^{\circ} \mathrm{C}, 20^{\circ} \mathrm{C}\right.$, and $\left.35^{\circ} \mathrm{C}\right)$. This table lists some parameters of the mixtures, such as $w / c$ (water/cement ratio), $w / p$ (water/powder ratio) and $c / p$ (cement/powder ratio). Powder content $p$ is the sum of both cement and filler materials.

Figure 1 shows the particle size distribution of the different cements and fillers. Table $\mathbf{2}$ summarizes the chemical properties of these materials. The mineral composition of the three cements is given as well, as 
calculated by means of Bogue's formulas (Neville 1995).

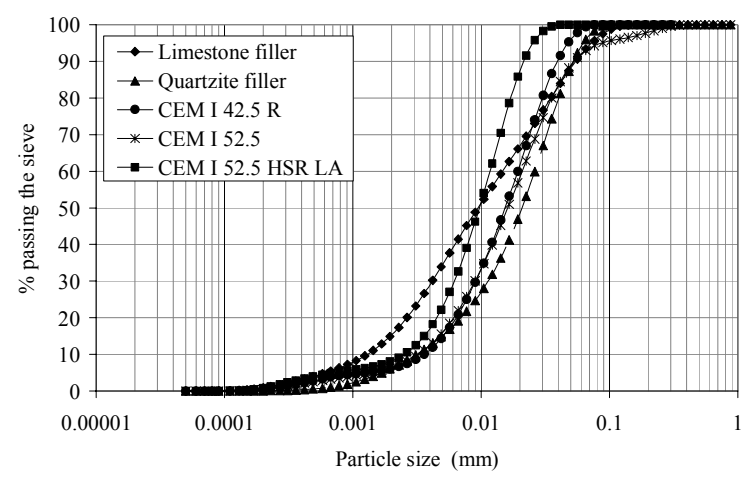

Fig. 1 Particle size distribution of cements and fillers.

Table 1 Composition of powder mixes used in isothermal tests.

\begin{tabular}{|l|c|c|c|c|}
\hline & Mix 1 & Mix 2 & Mix 3 & Mix 4 \\
\hline cement (g) & 7.5 & 4.5 & 4.5 & 2.5 \\
\hline filler (g) & - & 3 & 3 & 5 \\
\hline water (g) & 3.75 & 2.25 & 3.75 & 3.75 \\
\hline w/c & 0.5 & 0.5 & 0.83 & 1.5 \\
\hline w/p & 0.5 & 0.3 & 0.5 & 0.5 \\
\hline c/p & 1.0 & 0.6 & 0.6 & 0.33 \\
\hline
\end{tabular}

Table 2 Chemical properties of cements and fillers.

\begin{tabular}{|c|c|c|c|c|c|}
\hline & $\begin{array}{c}\text { CEM } \\
\text { I42.5R } \\
\%\end{array}$ & $\begin{array}{c}\text { CEM } \\
\text { I52.5 } \\
\%\end{array}$ & $\begin{array}{c}\text { CEM } \\
\text { I52.5 } \\
\text { HSR } \\
\text { LA } \\
\%\end{array}$ & $\begin{array}{c}\text { LF } \\
\%\end{array}$ & $\begin{array}{c}\text { QF } \\
\%\end{array}$ \\
\hline $\mathrm{CaO}$ & 61.53 & 63.95 & 64.23 & - & 0.02 \\
\hline $\mathrm{SiO}_{2}$ & 19.59 & 20.29 & 20.80 & 0.80 & 99.5 \\
\hline $\mathrm{Al}_{2} \mathrm{O}_{3}$ & 4.99 & 4.52 & 3.55 & 0.17 & 0.20 \\
\hline $\mathrm{Fe}_{2} \mathrm{O}_{3}$ & 2.98 & 2.35 & 3.94 & 0.10 & 0.03 \\
\hline $\mathrm{MgO}$ & 0.78 & 2.22 & 2.40 & 0.50 & - \\
\hline $\mathrm{K}_{2} \mathrm{O}$ & 0.87 & 0.94 & 0.50 & - & 0.04 \\
\hline $\mathrm{Na}_{2} \mathrm{O}$ & 0.36 & 0.20 & 0.17 & - & - \\
\hline $\mathrm{SO}_{3}$ & 3.29 & 3.35 & 2.74 & - & - \\
\hline $\mathrm{Cl}^{-}$ & 0.080 & 0.015 & 0.014 & 0.002 & - \\
\hline $\mathrm{CaCO}_{3}$ & - & - & - & 98.00 & - \\
\hline & & & & & \\
\hline $\mathrm{C}_{3} \mathrm{~S}$ & 58.2 & 59.0 & 60.6 & - & - \\
\hline $\mathrm{C}_{2} \mathrm{~S}$ & 12.7 & 12.6 & 16.6 & - & - \\
\hline $\mathrm{C}_{3} \mathrm{~A}$ & 8.19 & 8.01 & 2.75 & - & - \\
\hline $\mathrm{C}_{4} \mathrm{AF}$ & 9.1 & 9.4 & 13.1 & - & - \\
\hline & & & & & \\
\hline $\mathrm{m}^{2} / \mathrm{kg}$ & 281 & 286 & 418 & 526 & 360 \\
\hline $\mathrm{LF}_{2} \mathrm{Lim}$ & & & & \\
\hline
\end{tabular}

LF : Limestone filler

QF : Quartzite filler

\section{Results of isothermal hydration tests}

Figures 2 to $\mathbf{5}$ show the heat production rate $q(\mathrm{~J} / \mathrm{gh})$ as a function of time $t$, as experimentally obtained in the isothermal hydration tests at $20^{\circ} \mathrm{C}$. Similar curves are obtained for the tests at $10^{\circ} \mathrm{C}$ and $35^{\circ} \mathrm{C}$. A more fundamental parameter than time is the degree of hydration $\alpha$, defined as the cement fraction that has reacted. Due to difficulties in experimentally determining $\alpha$, in this study the degree of reaction $r$ is used as a parameter. $r$ is defined as the fraction of the heat of hydration that has been released at any point during testing (De Schutter and Taerwe 1995, De Schutter 1996, Van Breugel 1991, Van Breugel 1995):

$$
r(t)=\frac{Q(t)}{Q_{\max }}=\frac{1}{Q_{\max }} \int_{0}^{t} q(t) d t
$$

In order to study the effect of the filler on the heat development of the hydrating cement, some numerical results are summarized in Tables 3 and $\mathbf{4}$. In these tables, the mixture label starts with a number that corresponds to the composition mix numbers listed in Table 1. The mixture label also indicates the cement type and the filler type ( $\mathrm{LF}=$ limestone filler, $\mathrm{QF}=$ quartzite filler). Table 3 gives the maximum heat production rate $\mathrm{q}_{\max }$

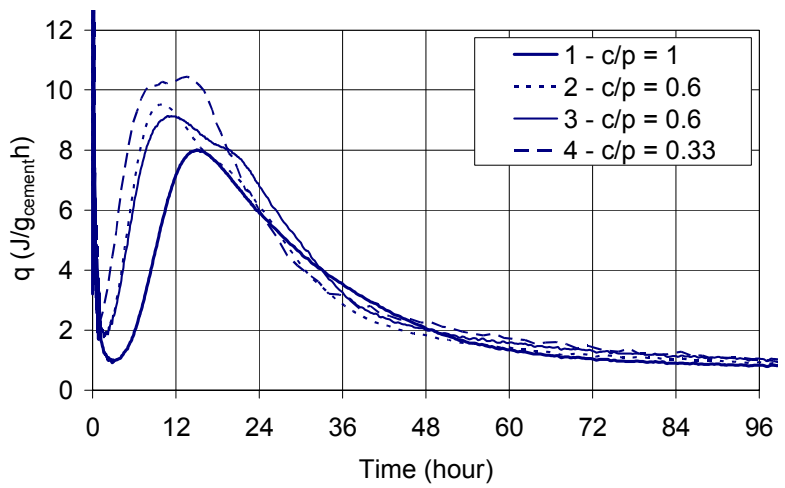

Fig. 2 Heat production rate for mixtures with CEM I 42.5 $\mathrm{R}$ and limestone filler at $20^{\circ} \mathrm{C}$.

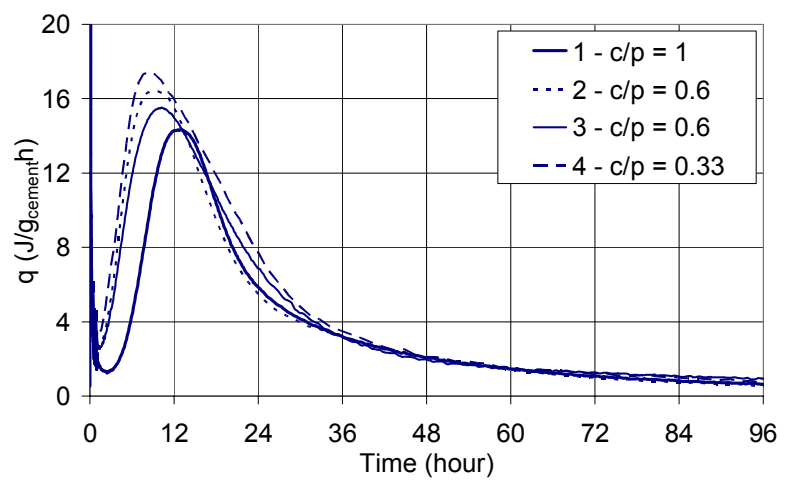

Fig. 3 Heat production rate for mixtures with CEM I 52.5 and limestone filler at $20^{\circ} \mathrm{C}$. 
$\left(\mathrm{J} / \mathrm{g}_{\text {cement }} \mathrm{h}\right)$ for the various mixes at the three testing temperatures. Table 4 gives the total heat of hydration $\mathrm{Q}_{\max }\left(\mathrm{J} / \mathrm{g}_{\text {cement }}\right)$ at the end of the test.

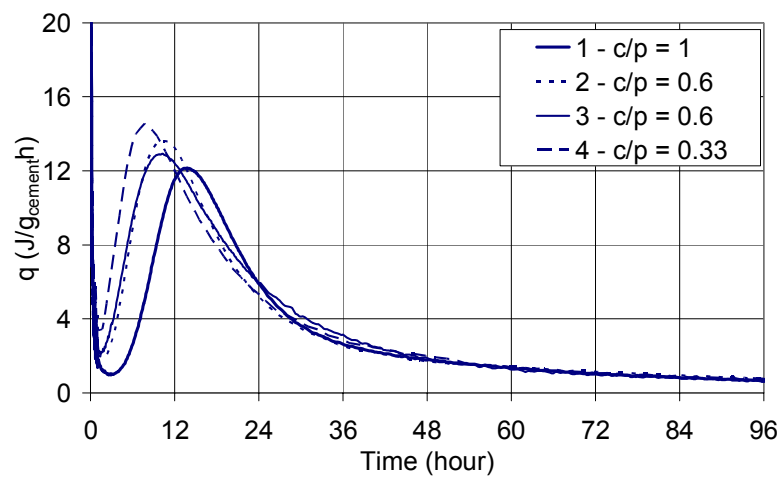

Fig. 4 Heat production rate for mixtures with CEM I 52.5 HSR LA and limestone filler at $20^{\circ} \mathrm{C}$.

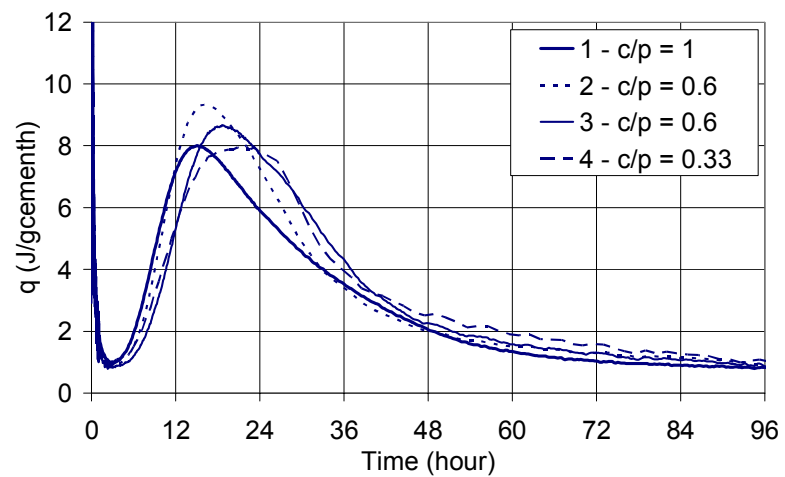

Fig. 5 Heat production rate for mixtures with CEM I 42.5 $\mathrm{R}$ and quartzite filler at $20^{\circ} \mathrm{C}$.

Table 3 Maximum heat production rate $q_{\max }\left(\mathrm{J} / \mathrm{g}_{\text {cement }} \mathrm{h}\right)$.

\begin{tabular}{|c|c|c|c|}
\hline Mixture & $\begin{array}{c}\mathrm{q}_{\max } \text { at } \\
10^{\circ} \mathrm{C}\end{array}$ & $\begin{array}{c}\mathrm{q}_{\max } \text { at } \\
20^{\circ} \mathrm{C}\end{array}$ & $\begin{array}{c}\mathrm{q}_{\max } \text { at } \\
35^{\circ} \mathrm{C}\end{array}$ \\
\hline 1/ 42.5R - LF & 4.03 & 8.01 & 17.15 \\
\hline 2/ 42.5R - LF & 4.81 & 9.54 & 19.40 \\
\hline 3/ 42.5R - LF & 5.07 & 9.14 & 21.90 \\
\hline 4/ 42.5R - LF & 5.40 & 10.48 & 27.87 \\
\hline 1/ 52.5 - LF & 7.20 & 14.32 & 30.06 \\
\hline 2/ 52.5 - LF & 8.57 & 16.42 & 33.54 \\
\hline 3/ 52.5 - LF & 8.26 & 15.52 & 34.58 \\
\hline 4/ 52.5 - LF & 8.53 & 17.49 & 35.02 \\
\hline $1 / 52.5 \mathrm{HSR}$ LA - LF & 6.42 & 12.14 & 23.44 \\
\hline 2/ 52.5HSR LA - LF & 7.37 & 13.62 & 27.44 \\
\hline 3/ 52.5HSR LA - LF & 7.05 & 12.93 & 26.04 \\
\hline 4/ 52.5HSR LA - LF & 7.07 & 14.54 & 23.58 \\
\hline 1/ 42.5R - QF & 4.03 & 8.01 & 17.15 \\
\hline 2/ 42.5R - QF & 4.76 & 9.35 & 14.88 \\
\hline 3/ 42.5R - QF & 4.99 & 8.66 & 15.71 \\
\hline 4/ 42.5R - QF & 4.40 & 7.95 & 16.85 \\
\hline
\end{tabular}

Table 4 Total heat $Q_{\max }\left(\mathrm{J} / \mathrm{g}_{\text {cement }}\right)$.

\begin{tabular}{|c|c|c|c|c|}
\hline Mixture & $\begin{array}{l}\mathrm{Q}_{\max } \text { at } \\
10^{\circ} \mathrm{C}\end{array}$ & $\begin{array}{l}Q_{\max } \text { at } \\
20^{\circ} \mathrm{C}\end{array}$ & $\begin{array}{l}Q_{\max } \text { at } \\
35^{\circ} \mathrm{C}\end{array}$ & $\begin{array}{c}\text { Theor. } \\
\text { heat at } \\
\text { complete } \\
\text { hydration }\end{array}$ \\
\hline 1/ 42.5R - LF & 256.8 & 280.8 & 289.0 & 421.5 \\
\hline 2/ 42.5R - LF & 291.4 & 319.1 & 313.6 & 421.5 \\
\hline $3 / 42.5 \mathrm{R}-\mathrm{LF}$ & 317.5 & 341.3 & 353.2 & 421.5 \\
\hline 4/ 42.5R - LF & 349.6 & 365.0 & 362.9 & 421.5 \\
\hline $1 / 52.5-\mathrm{LF}$ & 342.7 & 357.1 & 367.4 & 442.8 \\
\hline $2 / 52.5-\mathrm{LF}$ & 396.0 & 402.6 & 383.4 & 442.8 \\
\hline $3 / 52.5-\mathrm{LF}$ & 413.9 & 430.3 & 440.2 & 442.8 \\
\hline 4/ $52.5-\mathrm{LF}$ & 456.8 & 468.2 & 461.3 & 442.8 \\
\hline $\begin{array}{c}\text { 1/ 52.5HSR LA } \\
\text { - LF }\end{array}$ & 297.4 & 311.9 & 331.0 & 431.2 \\
\hline $\begin{array}{c}\text { 2/ 52.5HSR LA } \\
\text { - LF }\end{array}$ & 344.0 & 349.6 & 354.6 & 431.2 \\
\hline $\begin{array}{c}\text { 3/ 52.5HSR LA } \\
- \text { LF }\end{array}$ & 354.6 & 362.1 & 378.2 & 431.2 \\
\hline $\begin{array}{c}\text { 4/ 52.5HSR LA } \\
\text { - LF }\end{array}$ & 372.5 & 377.9 & 352.9 & 431.2 \\
\hline 1/ 42.5R - QF & 256.8 & 280.8 & 389.2 & 421.5 \\
\hline 2/ 42.5R - QF & 283.2 & 319.6 & 278.0 & 421.5 \\
\hline 3/ 42.5R - QF & 330.1 & 324.7 & 336.2 & 421.5 \\
\hline 4/ 42.5R - QF & 323.0 & 331.6 & 401.5 & 421.5 \\
\hline
\end{tabular}

\section{Discussion}

\subsection{Reaction mechanism}

From the results given in Figs. 2 to $\mathbf{5}$ and from the corresponding results at different temperatures, it is clear that the reaction mechanism of hydrating cement may in some cases be altered due to the presence of filler. This is evident when looking at the results obtained with the CEM I 42.5 R combined with limestone filler. When limestone filler is added to the cement, the induction period is shortened considerably, and an extra hydration peak occurs after approximately 22 hours for mixes 2 and 3, and after approximately 15 hours for Mix 4 . In the latter case, the second, extra peak has a heat production rate that is even slightly higher than that of the first peak. At $35^{\circ} \mathrm{C}$, this effect is even more pronounced. This can lead to the conclusion that the more limestone filler is added (and the lower the c/p) and the higher the testing temperature, the higher the production rate of the extra peak.

Alteration of the hydration reaction can also be noticed for the tests using CEM I 52.5, although it is much less pronounced. For CEM I 52.5 HSR LA, no alteration of the hydration reaction with the occurrence of a second hydration peak is observed. Unlike the limestone filler, the quartzite filler does not seem to influence the induction period, and apart from a slight waving of the curve of the hydration rate in some cases, no extra peak is observed.

Adiabatic tests carried out on a few mixes of selfcompacting concrete confirmed the alterations in the 
reaction mechanism found during the isothermal tests (Figure 6).

It is not clear at this time what is the driving force for the change in hydration mechanism and the occurrence of the extra hydration peak. A few different hypotheses can be drawn up.

In the literature, the influence of the filler material, and in particular limestone filler, on the hydration of the cement is in most cases considered to be limited to the rate of the reactions. Several authors mention that the setting kinetic is improved, the dormant period is reduced, and the hydration process within the first hours is accelerated (Billberg 2001, Sharma and Pandey 1999, Sari et al. 1999, Kadri et al. 2002a). Kadri et al. (2002b) suppose that the filler particles promote sites of heterogeneous nucleation to precipitate more or less crystallized hydrates, and in this way accelerate the hydration reaction.

A number of hypotheses for the occurrence of the second hydration peak can be followed. The noticed effect may be related to the hydration of the $\mathrm{C}_{3} \mathrm{~A}$ in the cement. Bensted (1987) indicates that a $\mathrm{C}_{3} \mathrm{~A}$ content of more than $12 \%$ results in a visible extra hydration peak during a $20^{\circ} \mathrm{C}$ isothermal hydration test. Past research (De Schutter and Taerwe 1995, De Schutter 1996) has pointed out that this hydration peak, related to the transformation of ettringite into monosulphate, can also be observed for portland cements with lower $\mathrm{C}_{3} \mathrm{~A}$ content (e.g. $7.5 \%$ ) when tested at temperatures of $40^{\circ} \mathrm{C}$ to $50^{\circ} \mathrm{C}$. This transformation might be activated by the presence of the limestone filler, meaning that the hydration peak can occur at lower temperatures as well. In the case of portland cement CEM I 52.5 HSR LA, no extra peaks can be observed, and neither can any be observed in the case of pure cement and the mixes that include limestone filler. For the latter mixes, the $\mathrm{C}_{3} \mathrm{~A}$ content is indeed very low $(2.5 \%)$, which may confirm the hypothesis.

Another approach is starting from the principle that limestone filler is not inert and does not only act as an activator for some reactions, but actually takes part in the hydration reactions. Research carried out by Bonavetti et al. (2001) revealed that combined with

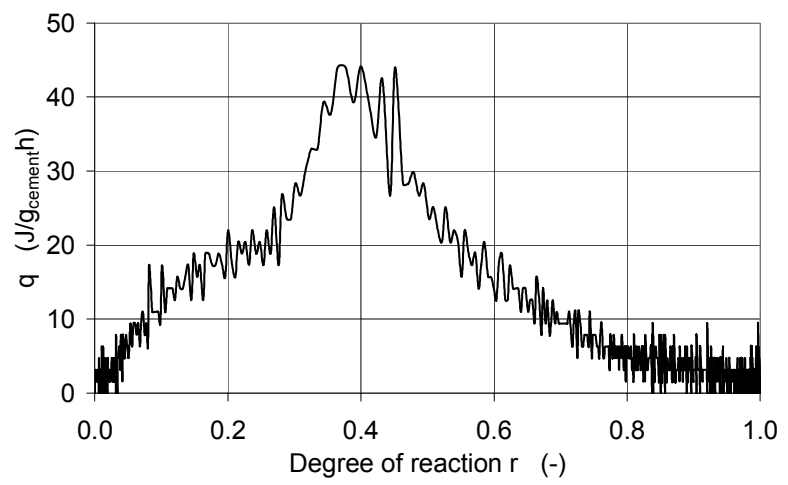

Fig. 6 Adiabatic hydration test using CEM I 42.5 R and limestone filler. portland cements, limestone filler modifies hydration reactions. Three days after mixing, monocarboaluminate was detected in the hydrating paste. This compound was also found by other researchers at different times during investigations of the $\mathrm{C}_{3} \mathrm{~A}$ content of cement. This hydration product is probably supplied by the transformation of monosulphoaluminate to monocarboaluminate owing to the greater stability of the latter compound. This reaction might cause the second hydration peak detected in the isothermal hydration tests on CEM I $42.5 \mathrm{R}$ and CEM I 52.5.

More details about these different hypotheses can be found in (Poppe 2004).

\subsection{Heat production rate}

A more detailed investigation of the maximum heat production rates during the isothermal tests (Table 3) leads to the finding that this maximum rate also seems influenced by the addition of limestone filler. Addition of limestone filler causes an increase in the maximum hydration production rate, unlike when quartzite filler is added, in which case the maximum hydration production rate hardly changes with varying $c / p$ ratios. When presenting the values of $q_{\max }$ at $20^{\circ} \mathrm{C}$ for the cementlimestone combinations in a diagram as a function of the $\mathrm{c} / \mathrm{p}$ ratio, there seems to be a linear relationship (Fig. 7).

\subsection{Cumulative heat}

The values of the cumulative heat at the end of the tests are given in Table 4 for the different mixtures. The theoretical cumulative heat at complete cement hydration can be estimated as the sum of the heats released during the hydration of the individual cement constituents (Van Breugel 1991). It can be noticed that more heat is released for the mixtures with added limestone than for the mixtures with cement and water. This can be explained by the different w/c ratios of the various cement-filler mixtures. In the case of CEM I 52.5, it can be noticed that for mixture 4 the experimentally obtained cumulative heat is higher than the theoretical heat at complete hydration of the cement. The reason for this finding is not clear at this time.

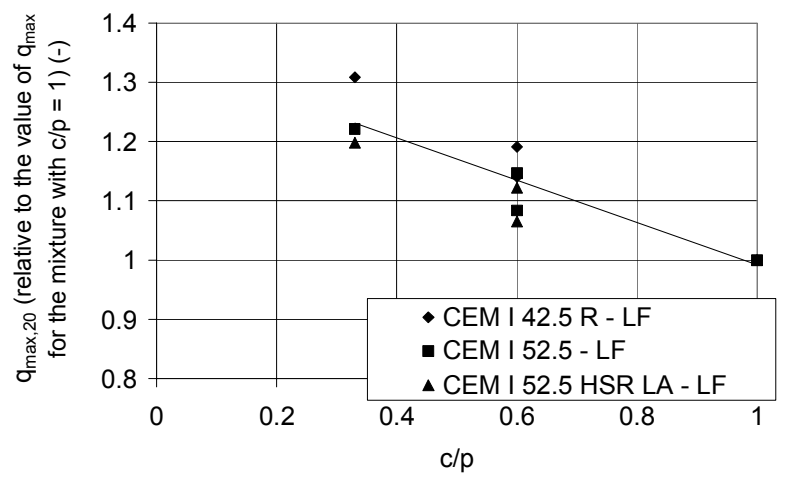

Fig. 7 Maximum heat production rate $\mathrm{q}_{\max }$ at $20^{\circ} \mathrm{C}$. 


\section{Hydration model}

The hydration model developed in (De Schutter 1996) was used for further evaluation of the hydration process in SCC in comparison with TC. In this model, where the first wetting peak is not taken into account and therefore eliminated for further modelling (De Schutter and Taerwe 1995, De Schutter 1996), the heat production rate of a portland cement is calculated as follows:

$$
\begin{aligned}
& q=q_{\max , 20} \cdot f(r) \cdot g(\theta) \\
& f(r)=c \cdot[\sin (r \pi)]^{a} \cdot \exp (-b r) \\
& g(\theta)=\exp \left[\frac{E}{R}\left(\frac{1}{293}-\frac{1}{273+\theta}\right)\right]
\end{aligned}
$$

where $q_{\text {max } 20}=$ maximum heat production rate at $20^{\circ} \mathrm{C}$, $\theta=$ temperature in ${ }^{\circ} \mathrm{C}, a, b$ and $c=$ parameters, $E=$ apparent activation energy, and $R=$ universal gas constant. This model describing the heat production rate allows conversion from a time scale to a scale of the rate of hydration $r(t)$ by stepwise integration of

$$
Q(t)=\int_{0}^{t} q(t) d t .
$$

For more details concerning this calculation, refer to Poppe 2004.

When looking into the results of the isothermal tests, it can be clearly seen that this hydration mechanism cannot be described as one function as done for a traditional concrete with portland cement. The presence of the limestone causes a second reaction, as previously discussed. This reaction has to be modelled separately, after which the superposition principle is applied in order to obtain the total cement reaction.

\subsection{First reaction}

When applying the model as in Eqs. (2), (3) and (4) to the first reaction of SCC hydration, the parameters calculated by the least squares method (in the same way as done for traditional concretes) seem to be influenced by the addition of the filler. When parameters $a_{1}$ and $c_{1}$, both calculated with the least squares method, are graphically interpreted as a function of $\mathrm{c} / \mathrm{p}$ for the different mixtures, like has been done for $q_{\max , 20}$, a second degree relationship is found to exist between these variables. This relationship still exists when $b_{1}$ is fixed at 3 . Figures 8 and 9 give the values for parameter $a_{1}$ with various cement types and filler types. Similar graphs exist for parameter $c_{1}$.

This means that the first hydration reaction can be described mathematically as follows:

$$
q_{1}=q_{1, \max , 20} \cdot c_{1} \cdot\left[\sin \left(r_{1} \pi\right)\right]^{a_{1}} \cdot \exp \left(-3 r_{1}\right)
$$

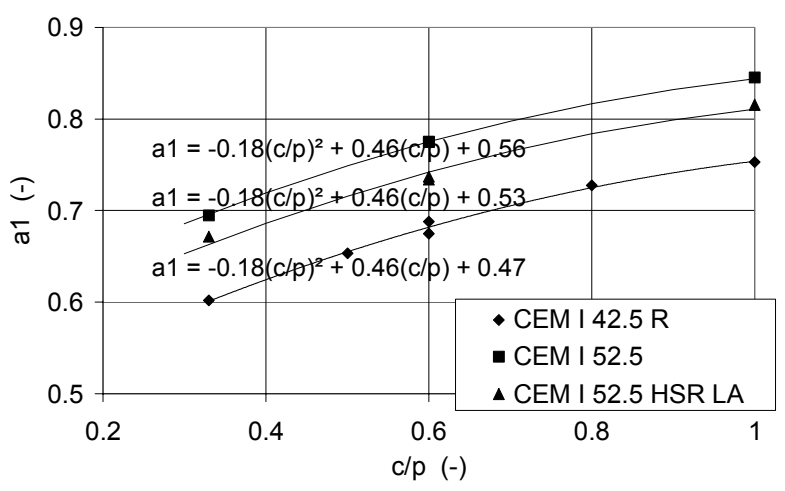

Fig. $8 \mathrm{a}_{1}$, limestone filler + various cement types.

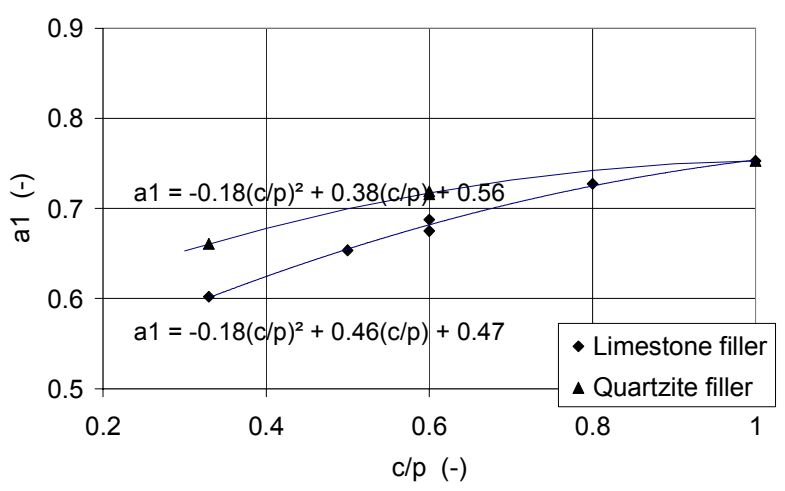

Fig. $9 \mathrm{a}_{1}$, CEM I 42.5 R + various filler types.

$$
\begin{gathered}
\cdot \exp \left[\frac{E_{1}}{R}\left(\frac{1}{293}-\frac{1}{273+\theta}\right)\right] \\
a_{1}=-0.18(c / p)^{2}+\gamma_{1}(c / p)+\gamma_{0} \\
c_{1}=-0.28(c / p)^{2}+\beta_{1}(c / p)+\beta_{0}
\end{gathered}
$$

where $\beta_{1}, \beta_{0}, \gamma_{1}$ and $\gamma_{0}=$ parameters depending on the type of cement and filler used in the mixture, $E_{1}=$ apparent activation energy of the first reaction, and $\mathrm{R}=$ universal gas constant.

The values for $\beta_{1}, \beta_{0}, \gamma_{1}$ and $\gamma_{0}$, determined with the least squares method are given in Table 4 . The values for $E_{1}$ for the different cements are determined using the maximal hydration rate at different temperatures resulting from the isothermal tests. These values are also given in Table 5.

\subsection{Second reaction}

The second reaction activated by the presence of the limestone filler in mixtures with portland cement CEM I $42.5 \mathrm{R}$ (cement with a considerable $\mathrm{C}_{3} \mathrm{~A}$-content) can be described as:

$$
q_{2}=q_{2, \max , 20} \cdot\left[\sin \left(r_{2} \pi\right)\right]^{a_{2}} \cdot \exp \left[\frac{E_{2}}{R}\left(\frac{1}{293}-\frac{1}{273+\theta}\right)\right]
$$


Table 5 Parameters of the hydration model for SCC.

\begin{tabular}{|l|c|c|c|c|}
\hline & $\begin{array}{c}\text { CEM I } \\
42.5 \mathrm{R} \\
-\mathrm{LF}\end{array}$ & $\begin{array}{c}\text { CEM I } \\
52.5 \\
-\mathrm{LF}\end{array}$ & $\begin{array}{c}\text { CEM I } \\
52.5 \text { HSR } \\
\text { LA - LF }\end{array}$ & $\begin{array}{c}\text { CEM I } \\
42.5 \mathrm{R} \\
-\mathrm{QF}\end{array}$ \\
\hline $\begin{array}{l}\mathrm{E}_{1} \\
(\mathrm{~kJ} / \mathrm{mol})\end{array}$ & 43.13 & 38.59 & 32.49 & 43.13 \\
\hline $\begin{array}{l}\mathrm{E}_{2} \\
(\mathrm{~kJ} / \mathrm{mol})\end{array}$ & 81.79 & - & - & - \\
\hline$\beta_{1}(-)$ & 0.69 & 0.69 & 0.69 & 0.56 \\
\hline$\beta_{0}(-)$ & 2.30 & 2.43 & 2.43 & 2.43 \\
\hline$\gamma_{1}(-)$ & 0.46 & 0.46 & 0.46 & 0.38 \\
\hline$\gamma_{0}(-)$ & 0.47 & 0.56 & 0.56 & 0.56 \\
\hline
\end{tabular}

where $q_{2, \max , 20}=$ maximum heat production rate of the second reaction at $20^{\circ} \mathrm{C}, a_{2}=$ parameter (equal to 0.71 ), $E_{2}=$ apparent activation energy of the second reaction (because the two reactions have a different temperature sensitivity, $E_{1}$ and $E_{2}$ do not have the same value), and $R$ $=$ universal gas constant. The values for $E_{2}$ can, similarly to the values for $E_{1}$, be determined from the results of the isothermal tests and are given in Table 5 .

Because the second reaction is much less pronounced during the hydration of the mixtures with CEM I 52.5, it is nearly impossible to separate the two reactions in a correct way. Therefore the reaction mechanism for these mixtures is modelled as one reaction.

\subsection{Combination of first and second reactions}

To describe the complete hydration rate $\mathrm{q}$ mathematically, the two different reactions have to be superposed. This superposition must take into account the fact that the second reaction does not start immediately after water addition, as can be seen in Fig. 1. Therefore $q_{2}$ has to be equal to zero until a certain degree of reaction of the first reaction $r_{1}(t)$ is reached. This degree of reaction $r_{1}(t)$ can be determined experimentally for the various mixtures. When presenting these values as a function of the $c / p$ factor, a clear linear relationship appears (Fig. 10). This means that $r_{1}$ can be expressed as:

$$
r_{1}=A \cdot c / p+B
$$

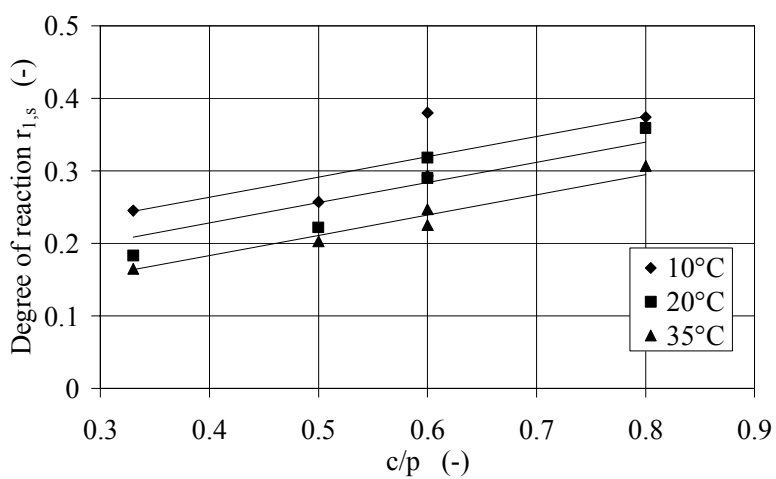

Fig. 10 Starting point $r_{1}(t)$ for second reaction.
The best fitting values for parameters $A$ and $B$ can be determined with the least squares method. Parameter $B$ in turn seems to be linearly dependent on the temperature of the isothermal test (Fig. 11), meaning:

$$
B=-0.0032 \cdot \theta+\delta_{0}
$$

where $\theta=$ temperature and $\delta_{0}=$ parameter depending on cement and filler type. For combination CEM I $42.5 \mathrm{R}$ with limestone filler considered during these test series, $A$ is equal to 0.28 and $\delta_{0}$ to 0.18 . This leads to the following expression for the degree of reaction $r_{1}(t)$ at which the second reaction starts:

$$
r_{l}=0.28 \cdot c / p-0.0032 \theta+0.18
$$

\subsection{Findings regarding hydration model}

Summarizing the foregoing discussions, the hydration rate of a self-compacting concrete can mathematically be described as follows:

First reaction

$$
\begin{aligned}
q_{1}= & q_{1, \max , 20} \cdot c_{1} \cdot\left[\sin \left(r_{l} \pi\right)\right]^{a_{1}} \cdot \exp \left(-3 r_{l}\right) . \\
& \cdot \exp \left[\frac{E_{1}}{R}\left(\frac{1}{293}-\frac{1}{273+\theta}\right)\right]
\end{aligned}
$$

Second reaction

$$
q_{2}=q_{2, \max , 20} \cdot\left[\sin \left(r_{2} \pi\right)\right]^{a_{2}} \cdot \exp \left\lfloor\frac{E_{2}}{R}\left(\frac{1}{293}-\frac{1}{273+\theta}\right)\right\rfloor
$$

(only for CEM I 42.5 R combined with limestone filler)

with parameters

$$
\begin{aligned}
& a_{1}=-0.18(c / p)^{2}+\gamma_{1}(c / p)+\gamma_{0} \\
& c_{1}=-0.28(c / p)^{2}+\beta_{1}(c / p)+\beta_{0}
\end{aligned}
$$

Complete reaction

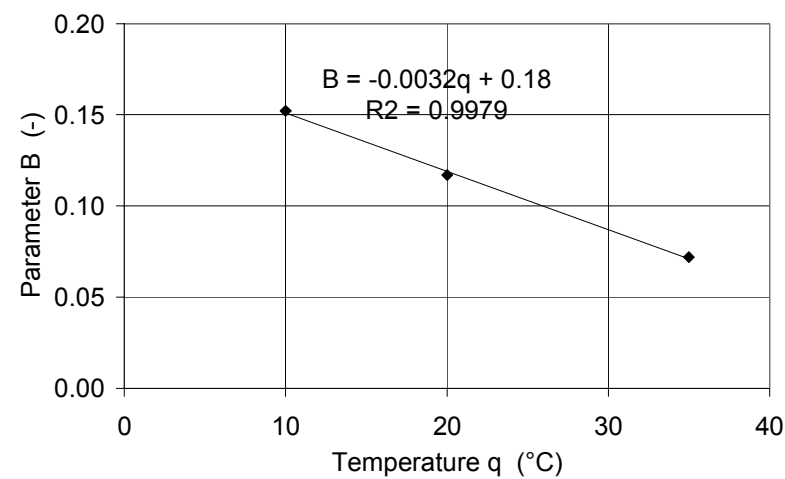

Fig. 11 Parameter B (CEM I 42.5 R - LF). 


$$
q=q_{1}+q_{2}
$$

(only for CEM I 42.5 R combined with limestone filler) with

$$
q_{2}=0 \text { as long as } r_{1}<0.28 \cdot c / p-0.0032 \cdot \theta+0.18(18)
$$

Comparison of the proposed model with the experimentally obtained results shows that the mathematical description of the hydration process leads to an accurate prediction (Fig. 12).

For the application of this hydration model to selfcompacting concrete in adiabatic conditions, further tests are needed so that the influence of the chemical admixtures on heat release may be included among the parameters of the model.

\section{Conclusions}

Based on isothermal and adiabatic hydration tests on self-compacting and traditional concrete, incorporating different types of portland cement, the following conclusions are obtained.

(1) In some cases, the reaction mechanism of portland cement is clearly influenced by the addition of limestone filler. The induction period is shortened and an extra heat production peak sometimes occurs, even at the lowest testing temperatures. These phenomena are not observed when quartzite filler is used in the mixes.

(2) The heat production rate of the second peak is clearly influenced by the presence of limestone filler. The greater the amount of filler and the higher the testing temperature, the more pronounced the peak. A linear dependency of the maximum heat production rate on the $\mathrm{c} / \mathrm{p}$ ratio is allowable in a first approximation.

(3) Because of the modification of the hydration process in the case of SCC, the hydration model developed for TC shows some discrepancy with experimental results when applied to the case of SCC. Using the results of the hydration tests, the model can be modified through inclusion of the second peak and adjustment of the parameters. Fixing parameter $b_{1}$ at 3 , parameters $a_{1}$

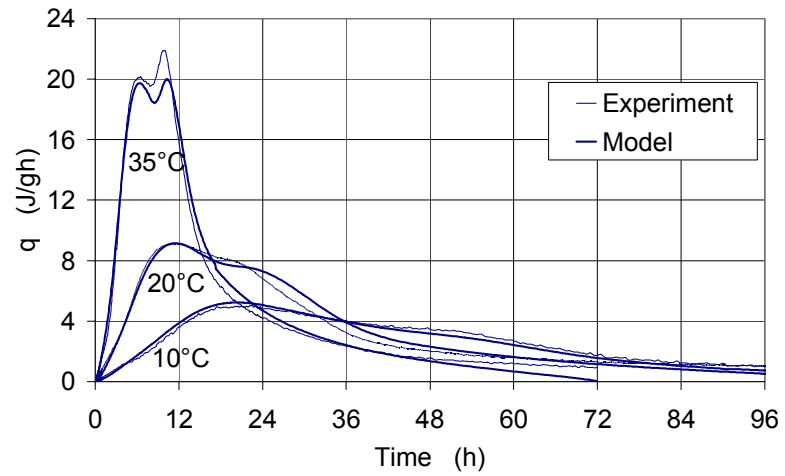

Fig. 12 Hydration of Mix 3, CEM I 42.5 R and LF. and $c_{1}$ seem to be dependent from $\mathrm{c} / \mathrm{p}$. The degree of reaction of the first reaction required for the second reaction to start can be described as a function of $\mathrm{c} / \mathrm{p}$ and the temperature $\theta$. In this part of the research, the influence of the chemical admixtures is not included yet. This will be the object of further investigations.

\section{References}

Bensted, J. (1987). "Some applications of conduction calorimetry to cement hydration." Advances in Cement Research, 1 (1), 35-44.

Billberg, P. (2001). "Influence of filler characteristics on SCC rheology and early hydration." In: K. Ozawa and M. Ouchi, Eds. Proceedings of the Second International RILEM Symposium on Self-compacting Concrete, Tokyo 2001, 285-294.

Bonavetti, V. L., Rahhal, V. H. and Irassar, E. F. (2001). "Studies on the carboaluminate formation in limestone filler-blended cements." Cement and Concrete Research, 31 (6) 853-859.

De Schutter, G. and Taerwe, L. (1995). "General hydration model for portland cement and blast furnace slag cement." Cement and Concrete Research, 25 (3) 593-604.

De Schutter, G. (1996). "Fundamental and practical study of thermal stress in hardening massive concrete elements." Doctoral thesis, Ghent University. (in Dutch)

Kadri, E. H., Aggoun, S. and Duval, R. (2002a). "Influence of grading and diameter size of admixture on the mechanical properties of cement mortars." In: V. Bilek and Z. Kersner, Eds. Proceedings of the International Symposium on Non-Traditional cement and concrete, Brno 2002, 306-313.

Kadri, E. H. and Duval, R. (2002b). "Effect of ultrafine particles on heat of hydration of cement mortars." ACI Materials Journal, 99 (2), 138-142.

Neville, A. M. (1995). "Properties of Concrete.” Pitman Publ. Ltd. London, fourth edition.

Noguchi, T. and Mori, H. (1998). "State-of-the-art report: Evaluation of fresh properties of selfcompacting concrete in laboratory and on site." In: K. Ozawa and M. Ouchi, Eds. Proceedings of the international workshop on self-compacting concrete, Kochi 1998, 97-110.

Okamura, H. and Ouchi, M. (1999). "Self-compacting concrete. Development, present use and future." In: A. Skarendahl and O. Petersson, Eds. Proceedings of the first International RILEM Symposium on Selfcompacting Concrete, Stockholm 1999, 3-14.

Poppe, A. -M. (2004). "Influence of fillers on hydration and properties of self-compacting concrete." Doctoral thesis, Ghent University. (in Dutch)

Sari, M., Prat, E. and Labastire, J. F. (1999). "Highstrength self-compacting concrete-Original solutions associating organic and inorganic admixtures." Cement and Concrete Research, 29 (6), 813-818. 
Sharma, R. L. and Pandey, S. P. (1999). "Influence of mineral additives on the hydration characteristics of ordinary portland cement." Cement and Concrete Research, 29 (9), 1525-1529.

Van Breugel, K. (1991). "Simulation of hydration and formation of structure in cement based materials."
Doctoral thesis, Delft University of Technology.

Van Breugel, K. (1995). "Numerical simulation of hydration and microstructural development in hardening cement-based materials - theory." Cement and Concrete Research, 25 (2), 319-331. 